\title{
Geochemical features of lakes located in an urbanised area of the Russian Arctic (Murmansk region)
}

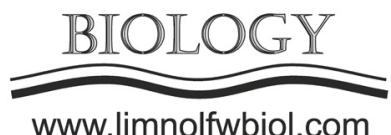

\author{
Guzeva A.V., ${ }^{1, *}$, Slukovskii Z.I. ${ }^{2,3}$, Myazin V.A. ${ }^{2}$ \\ ${ }^{1}$ Institute of Limnology of the Russian Academy of Sciences, Sevastyanova str.,9, 196105, Saint Petersburg, Russia \\ ${ }^{2}$ Institute of the North Industrial Ecology Problems of Kola Science Center of RAS, 184209 Apatity, Russia \\ ${ }^{3}$ Institute of Geology of Karelian Research Centre of RAS, 185910 Petrozavodsk, Russia
}

\begin{abstract}
Murmansk is a significant industrial region with developed infrastructure located in the Russian Arctic. Small lakes of the city are actively used by the population for economic purposes. Therefore, comprehensive geochemical research of lake systems is one of the crucial aspects of environmental monitoring. We analyzed trace metal content and petroleum hydrocarbons content in sediments of Murmansk five lakes. Fieldwork was conducted in 2019. Sediment cores were divided into 5-cm layers. For analysis, we used the ICP-MS and FTIR-methods. The research results showed that Lake Ledovoe is one of the most polluted urban lakes in Murmansk. Its sediment is highly enriched in petroleum hydrocarbons and trace metals. Potential bioavailability of some toxic metals increases in the most recent sediment layers. Therefore, there is a high risk of secondary pollution of the lake and migration of pollutants along the food chains of the aquatic ecosystem.
\end{abstract}

Keywords: Murmansk region, lake sediments, petroleum hydrocarbons, trace metals

\section{Introduction}

Geochemical research of small lakes located in the urbinised territories of the Arctic is an important part of the comprehensive environmental monitoring of aquatic ecosystems. Layer-by-layer chemical analysis of lake sediment cores allows researchers to reconstruct temporary variations of the hydrochemical and geochemical parameters of lakes, including the content of hazardous pollutants (Rognerud et al., 2000). Sediment can become a source of secondary pollution of the lake ecosystem if there are changes in the physicochemical parameters of the environment, particularly from anthropogenic activity. Murmansk is one the biggest city in the Russian Arctic, with developed infrastructure and industrial facilities. Therefore, priority pollutants of the territory are toxic metals, petroleum, polycyclic aromatic hydrocarbons, and the volatiles $\left(\mathrm{SO}_{2}\right.$ and $\left.\mathrm{NO}_{2}\right)$. The lakes located within the city of Murmansk are actively used by the population for recreational and economic purpose but information on the environmental condition of the water bodies is limited.

\section{Materials and methods}

We study geochemical features of sediments of five small lakes of Murmansk (Severnoe, Semenovskoe, Srednee, Okunevoe and Ledovoe) in terms of total trace metals content, chemical fractions of metals (Tessier, 1979), and content of petroleum hydrocarbons. Sediment samples were collected by gravity corer Limnos during fieldwork in 2019 (Slukovskii et al., 2020). Sediment cores were divided into 5-cm layers. We used the ICP-MS method for trace metal content analysis and FTIR-method for analyses of petroleum hydrocarbon content.

\section{Results and discussion}

In all lakes, the upper layers $(0-15 \mathrm{~cm})$ of the cores were the most enriched in metals and petroleum hydrocarbons. However, the most critical situation was identified for Lake Ledovoe.

The content of oil products in the sediments of the lake varies from 14000 to $25000 \mathrm{mg} / \mathrm{kg}$, which characterizes them as dangerously contaminated (According to the Regional Standard "Norms and Criteria for Evaluating the Contamination of Bottom Sediments in Water Bodies of St. Petersburg" dated 22.07.1996) along the entire depth the sediment core $0-30 \mathrm{~cm}$. Sediments of other lakes are characterized by the content of hydrocarbons as unpolluted or slightly polluted.

$\mathrm{V}, \mathrm{Ni}$, as well as $\mathrm{Pb}, \mathrm{Cd}$ and $\mathrm{Zn}$ are the priority pollutant metals in the Murmansk lakes. $\mathrm{V}$ and $\mathrm{Ni}$ are impurities in the fuel oil, which currently used at

*Corresponding author.

E-mail address: olina2108@mail.ru (A.V. Guzeva)

(C) Author(s) 2020. This work is distributed under the Creative Commons Attribution 4.0 License. 


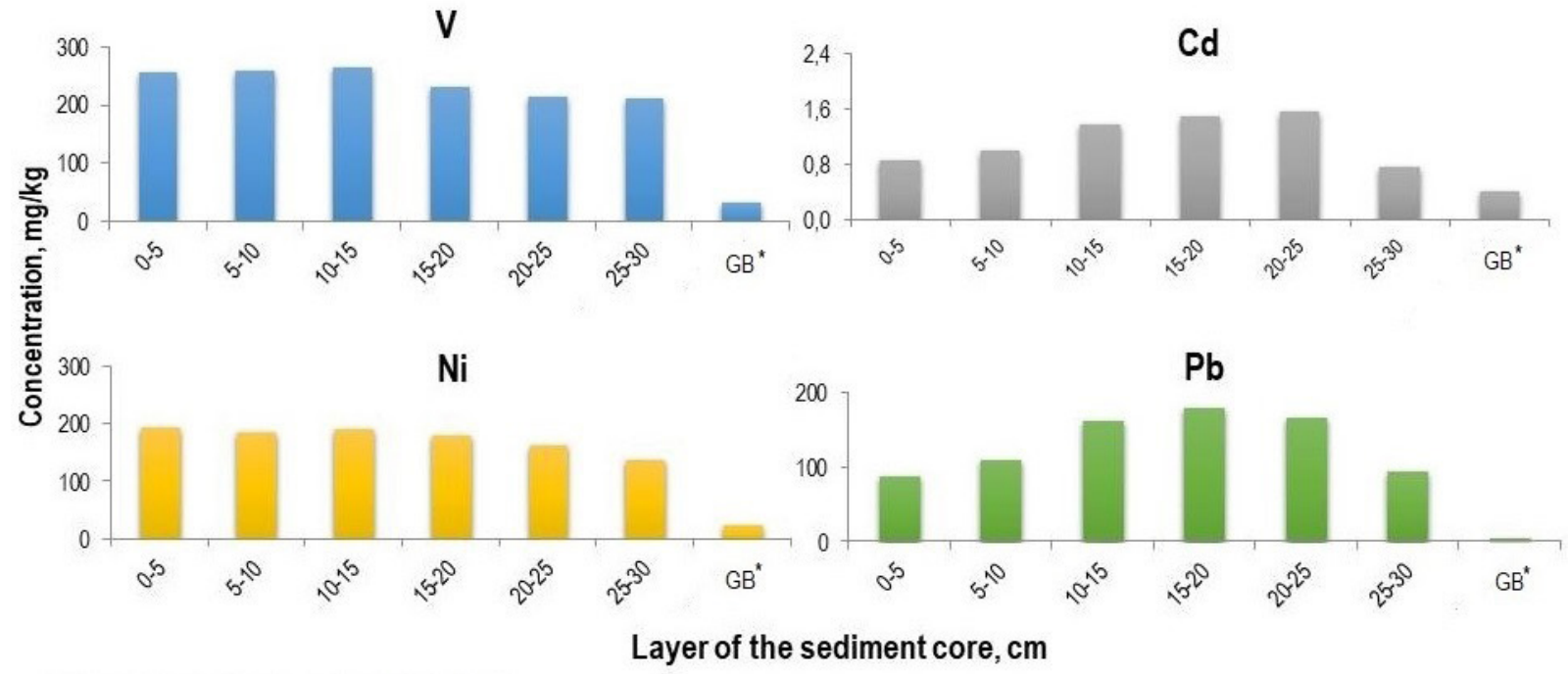

*GB - geochemical background for lake sediments

Fig.1. The total content $\mathrm{V}, \mathrm{Ni}, \mathrm{Cd}, \mathrm{Pb}$ in different layers of sediment core of Lake Ledovoe compared with the background for sediments of small lakes in Karelia

the Murmansk thermal power plant. $\mathrm{Pb}$ and $\mathrm{Cd}$ are indicators of the environmental impact of transport infrastructure. $\mathrm{Pb}$ was used, as tetraethyllead, as an additive in gasoline. At present, lead-containing gasoline is not used in Russia but the sediments of lakes in urban areas in the north of Russia are still contaminated with $\mathrm{Pb}$. In Lake Ledovoe, over the entire depth of the core, significant excess the geochemical background concentration (more than 30 times for $\mathrm{Pb}$; 4 - 8 times for $\mathrm{V}$, Ni and $\mathrm{Cd}$ ) was revealed (Fig. 1). We used background concentrations of the metals for small lakes of Republic of Karelia (Slukovskii, 2020) because it has a similar geological structure. Furthermore, we evaluated the potential bioavailability of toxic metals. Ni and Cd turned out to be the most mobile. The share of bioavailable forms for them can be up $20-30 \%$ of the total content and it is increasing in the upper (recent) layers of the core. In contrast, $\mathrm{V}$ and $\mathrm{Pb}$ are characterized by stable chemical bonds with the components of sediments. The part of potentially bioavailable forms for them does not exceed $1-2 \%$ over the entire depth of the core.

\section{Conclusion}

The research results showed that Lake Ledovoe is one of the most polluted urban lakes in Murmansk. It is located in the zone of intensive influence of both a thermal power plant and transport infrastructure (roads, car service and gas stations). Its sediment is highly enriched in petroleum hydrocarbons and trace metals. Moreover, the mobility of some toxic metals increases in the most recent sediment layers. In view of the intense anthropogenic impact on the physical and hydrochemical parameters of the aquatic ecosystem, there is a high risk of secondary pollution of the lake and migration of pollutants along the food chains of the ecosystem.

\section{Acknowledgements}

This research is supported by the Russian Science Foundation [project no. 19-77-10007] (analysis of total concentrations of trace metals and petroleum hydrocarbons) and the Russian Foundation for Basic Research [project no. 18-05-00897] (analysis of different forms of metals).

\section{References}

Rognerud S., Hongve D., Fjeld E., Ottesen R.T. 2000. Trace metal concentrations in lake and overbank sediments in southern Norway. Environmental Geology 39 (7): 723-732. DOI: https://doi.org/10.1007/s002540050486

Slukovskii Z.I., 2020. Background concentrations of heavy metals and other chemical elements in the sediments of small lakes in the south of Karelia, Russia. Vestnik of MSTU 23(1): 80-92. https://doi. org/10.21443/1560-9278-2020-23-1-80-92

Slukovskii Z., Dauvalter V., Guzeva A. et al. 2020. The Hydrochemistry and Recent Sediment Geochemistry of Small Lakes of Murmansk, Arctic Zone of Russia. Water 12: 1130. https://doi.org/10.3390/w12041130

Tessier A. 1979. Sequential extraction procedure for the speciation of particulate trace metals. Analytical Chemistry 51(7): 844-851. https://doi.org/10.1021/ac50043a017 